Review

\title{
Realistic and critical review of the state of systemic anti- microbial peptides
}

\author{
Guangshun Wang*, Abraham Fikru Mechesso \\ Department of Pathology and Microbiology, College of Medicine, University of Nebraska Medical Center, 985900 \\ Nebraska Medical Center, Omaha, NE 68198-5900, USA \\ *Corresponding author email: gwang@unmc.edu
}

Received: December 17, 2021; Revised: January 14, 2022; January 20, 2022

\begin{abstract}
Antimicrobial peptide research remains active not only because of the growing antibiotic resistance problem but also our desire to understand the role of innate immune peptides in host defense. While numerous peptides are currently under active development for topical use, this article highlights peptides with systemic efficacy. The scaffolds of these peptides range from linear to cyclic forms. The neutropenic mouse model is well established to illustrate antimicrobial efficacy from direct killing. The majority of tests, however, are conducted using normal mice so that both direct antimicrobial and immune regulatory effects can be characterized. These systemic examples underscore the possibility of adding new candidates to the list of the existing peptide antibiotics to more effectively combat antibiotic-resistant bacteria, fungi, and parasites.

(C2021 by the authors. This article is an open-access article distributed under the terms and conditions of the Creative Commons Attribution license (http://creativecommons.org/licenses/by/4.0/).
\end{abstract}

\section{Keywords}

Antibiotics; antimicrobial peptides; peptide design; MIC; PK; PD; systemic efficacy; toxicity; intravenous injection

\section{Introduction}

The current SARS-CoV-2 pandemic is a reminder to human beings that pathogenic microbes can have a tremendous impact on every aspect of our society. In addition to viruses, antibiotic-resistant bacteria, fungi and parasites constitute a new potential threat. It is projected that 10 million people could die from untreatable infections by 2050 [1]. Consequently, it becomes urgent to search for novel antimicrobials.

Innate immune antimicrobial peptides (AMPs) play a critical role in protecting the hosts from infection $[2,3]$. Their lasting efficacy rejuvenates our interest in developing them into novel antibiotics. Indeed, some peptide antibiotics such as gramicidin, vancomycin, daptomycin and colistin are already in clinical use [4]. According to the updated antimicrobial peptide database (https://aps.unmc.edu), over 3000 such peptides have been discovered and characterized from natural sources, ranging from bacteria to animals $[5,6]$. Many AMPs are cationic and possess broad-spectrum antimicrobial activity against both Gram-positive and Gramnegative bacteria. Some peptides, however, eliminate only Gram-positive or Gram-negative bacteria. Frequently, AMPs consist of both basic and hydrophobic amino acids. While basic amino acids initiate 
anionic bacterial recognition, hydrophobic amino acids are important for subsequent peptide anchoring into membranes. This is accompanied by a structural transition from random coils to an amphipathic $\alpha$ helical structure $[2,3,7]$. In addition to the $\alpha$ family, there are three other types of structural families: $\beta, \alpha \beta$, and non- $\alpha \beta$ [8]. Representative structures for these four families can be viewed on the face page of the AMP database website above. Some AMPs have a folded structure even in an aqueous solution. One molecular mechanism results from the forced folding of disulfide bonds. As a consequence, $\alpha$-defensins are known to adopt $\beta$-sheet structures. Beta-defensins, longer than $\alpha$-defensins, can incorporate an $\alpha$-helical element to generate a mixed $\alpha \beta$ fold. Like helical peptides, defensins have an effect on membranes as well. Some defensins, however, work by inhibiting cell wall synthesis $[9,10]$. There are also AMPs that form neither a regular $\alpha$-helix nor a $\beta$-sheet structure. Proline-rich peptides are such examples that inhibit bacterial growth by binding to ribosomes [11]. The structural diversity of AMPs offers numerous R\&D opportunities for developing novel peptide antibiotics.

This minireview highlights AMPs with the potential to treat systemic infections. We discuss peptide toxicity, in vivo efficacy, and pharmacokinetic (PK) and pharmacodynamic (PD) studies. These examples support the potential of engineered AMPs as novel systemic antibiotics.

\section{Peptide design: antimicrobial robustness, selectivity and stability}

The basic goal of peptide design is to identify potent peptides with minimal or no toxic effects on normal cells. It is evident that basic and hydrophobic amino acids are the two key elements in designing amphipathic antimicrobial peptides $[7,12,13]$. Our current knowledge implies that basic amino acids are key to the inhibition and killing of Gram-negative bacteria, whereas hydrophobic amino acids are critical to eliminating Gram-positive bacteria such as methicillin-resistant Staphylococcus aureus (MRSA) [14]. Although reducing peptide hydrophobicity is a general strategy to improve peptide cell selectivity [15], basic amino acids also play a role [16]. Hence, the finally designed peptide achieves an optimal combination of hydrophobic and basic amino acids. Selected peptides discussed in this review are listed in Table 1 . These peptides were obtained by modifying natural peptides or designed based on the key elements of AMPs. A3APO, Onc72, Onc112, and Api137 are derived from proline-rich peptides originally discovered in insects [1719]. Gomesin is a short $\beta$-hairpin peptide isolated from scorpions [20]. AMPR-11 is a peptide derived from mitochondrial non-selective channel Romo-1 [21]. C10-KR8d is a lipopeptide designed based on the minimal antibacterial peptide KR-12 of human cathelicidin LL-37 [22], whereas OH-CATH30 is a truncated fragment of the king cobra cathelicidin OH-CATH [23]. Some peptides are de novo designed. WLBU2 is a synthetic peptide designed using valine, tryptophan, and arginine [24]. DFT503 and DFT561 [25] are derivatives of the DFTamP1, which is the first database filtering technology designed peptide obtained by extracting the key parameters (peptide length, charge, hydrophobicity, and structure) from the antimicrobial peptide database [26]. Horine and verine were designed by combining database filtering with structural knowledge [27].

Another important goal of peptide design is to improve peptide stability to proteases. Several strategies are utilized to enhance peptide stability: terminal capping, incorporation of non-standard amino acids, and peptide cyclization [28]. For example, the incorporation of D-amino acids increased the half-life $\left(t_{1 / 2}\right)$ of horine from $\sim 10 \mathrm{~min}$ (L-form) to $60 \mathrm{~min}$ (D-form) in vivo [27]. In the case of C10-KR8, the D-form is preferred over the L-form since the D-from did not bind as many serum components as the L-form based on mass spectrometric studies [22]. There are also other methods to improve peptide stability. While peptide mimicries may be made to eliminate susceptible peptide bonds entirely [29-31], formulations can protect peptides from protease degradation [32,33]. 
Subsequently, after peptide optimization, it is necessary to test peptide antimicrobial robustness. This is because AMPs such as LL-37 are known to lose activity in the presence of physiological salts, serum, and under acidic conditions [22,24,34]. It is anticipated that the peptides are more likely to display in vivo efficacy if they can retain antimicrobial activity under such conditions. To identify candidates with such properties, we assembled a pipeline of in vitro filters by measuring peptide MIC values in rich media supplemented with salts, serum, and at an acidic $\mathrm{pH}$. We found that very few peptides retain antimicrobial activity under all these conditions. It was encouraging that our database-designed peptides that crossed these barriers did show systemic efficacy in vivo $[22,27]$.

\section{In vivo toxicity of designed antimicrobial peptides}

Nephrotoxicity of colistin is the major side effect of this antibiotic $[35,36]$. Therefore, there is a desire to develop the next generation of peptide antibiotics with minimized toxicity. To evaluate the peptide toxicity in vivo, the commonly used routes for peptide administration are intraperitoneal (i.p.), intravenous (i.v.), intramuscular (i.m.), and subcutaneous (s.c.) injections (Table 1). Of significant interest is the peptide toxicity after intravenous injection. For A3-APO, mice survived with severe transient side effects at 25 $\mathrm{mg} / \mathrm{kg}$ (i.p.), but a single dose of $50 \mathrm{mg} / \mathrm{kg}$ was lethal, indicating a maximum tolerated dose (MTD) was 20 $\mathrm{mg} / \mathrm{kg}$. It is equal to the No Observed Adverse Effect Limit (NOAEL) in this case. In the same model, the $50 \%$ lethal dose $\left(L_{50}\right)$ of colistin was found to be less than $40 \mathrm{mg} / \mathrm{kg}$ [17]. The $\mathrm{LD}_{50}$ of OH-CATH30 after i.p. injection was $120 \mathrm{mg} / \mathrm{kg}$ and mice survived when subcutaneously injected at $160 \mathrm{mg} / \mathrm{kg}$ [23]. The WLBU2 peptide was found to have an MTD of $12 \mathrm{mg} / \mathrm{kg}$ (i.v.) [24]. This is fourfold higher than the treatment dose at $3 \mathrm{mg} / \mathrm{kg}$. Four alternating D,L-cyclic peptides $(6752,6756,6853$ and 7251) displayed MTDs in the range of 20-25 mg/kg or above depending on the amino acid sequence [37]. These concentrations allowed a dosedependent treatment at $16 \mathrm{mg} / \mathrm{kg}$ or below. Likewise, teixobactin showed no sign of toxicity when administered intravenously at a single dose of $20 \mathrm{mg} / \mathrm{kg}$ [38]. A single i.v. injection of AMPR-11 (100 $\mathrm{mg} / \mathrm{kg}$ ), tenfold higher than the treatment dose into mice, did not show severe clinical signs of toxicity for 15 days [21]. After one week of daily i.p. injection at the treatment dose $(10 \mathrm{mg} / \mathrm{kg})$, horine showed no side effects on body weight, animal behavior, or kidney histology [27]. Although a slight body weight loss (12.1 \%) was noted after daily i.v. injection $(10 \mathrm{mg} / \mathrm{kg})$ for a week, we did not observe any other side effects. These results are encouraging and will lead to the discovery of novel peptides with further reduced toxicity and enhanced potency.

\section{Systemic efficacy of antimicrobial peptides}

While most candidates are developed for topical use, some laboratories have observed systemic efficacy for designed peptides (Table 1). Both neutropenic and normal mice are utilized for systemic efficacy evaluation. Neutropenic mice are a classic model to establish direct antimicrobial efficacy and for studying PK/PD of antibiotics since the immune effects are suppressed $[39,40]$. It is important to establish that bacteria had spread to different organs prior to antimicrobial treatment. After i.p. injection, Szabo and colleagues [17] found a 30-minute delay was sufficient for E. coli to spread all over the body of mice. Mor and colleagues observed the spread of Escherichia coli in neutropenic mice one-hour post i.p. infection [31]. We also detected MRSA or Klebsiella pneumoniae in different murine organs two hours post-infection $[25,27]$. Selsted and colleagues also found the dissemination of $K$. pneumoniae to various organs one-hour post i.p. infection [41]. The peptide efficacy is often reflected by a dose-dependent colony-forming unit (CFU) drop as well as the survival advantage of mice in the treated group relative to the untreated infected group. Using the neutropenic thigh model, Dartois et al. [37] made alternating D,L-cyclic peptides and observed a decrease of the $S$. aureus load by 2.1-3.0 log units after i.v. treatment ( $8 \mathrm{mg} / \mathrm{kg}$ ) two hours post 
i.m. infection. Although effective in vitro, two such peptides (1316 and 1150) failed to show in vivo activity, probably due to low bioavailability. Using the same model, Li et al. [23] tested the efficacy of OH-CATH30 immediately after thigh infection at 1,10 , and $20 \mathrm{mg} / \mathrm{kg}$ via a single s.c. treatment. In the protection experiment, the survival rate of mice decreased from $100 \%$ to $57-70 \%$ when the treatment time was delayed from one hour to four hours post i.p. infection (E. coli at $10^{8} \mathrm{CFU}$ ). Using CD-1 neutropenic mice infected with MRSA intraperitoneally, teixobactin (MIC $0.25 \mu \mathrm{g} / \mathrm{ml}$ against MRSA) shows dose-dependent efficacy (i.e., CFU decrease) after a single dose i.v. treatment two hours post-infection [38].

Mor observed systemic efficacy of the OAK peptide mimics in neutropenic mice but not two amphibian peptide derivatives [31]. Likewise, we did not observe systemic efficacy in this model for a human cathelicidin LL-37 derived peptide [25]. One possibility is that the peptide associates with other molecules in mice and is not available to attack bacteria. Our reasoning is in line with the molecular promiscuity of LL37 (binding to numerous molecular partners such as human serum proteins and nucleic acids) [22,24,34]. Similarly, indolicidin did not show a protective effect when treated in the free form. After formulation, however, it protected mice by $30 \%$ [32]. These results indicate that not all AMPs are able to display systemic efficacy in mice in the free form. Taking this into consideration, we then aimed at identifying more robust peptides that retain activity under various conditions by expanding the database filtering technology from in silico to in vitro. Our database-designed peptides are particularly effective against Gram-positive pathogens such as MRSA and vancomycin-resistant Enterococci (VRE). In addition, we discovered that an increase in cationic amino acids led to an increase in toxicity and a loss of in vivo activity of the DFTdesigned peptides in neutropenic mice [25]. In keeping with this low cationicity idea, we have designed even shorter peptides such as horine and verine to reduce production costs [27]. These two peptides share a similar amino acid composition but possess different amino acid sequences. They also have different 3D structures and activity spectra: horine mainly against Gram-positive MRSA and verine against both Grampositive and negative pathogens. During a five-day observation, a single dose injection of horine at 10 $\mathrm{mg} / \mathrm{kg}$ (i.p.) protects $87.5 \%$ mice infected with MRSA identical to vancomycin, whereas $81.8 \%$ mice infected with antibiotic-resistant $K$. pneumoniae E406-17 survived after a single dose of verine treatment $(15 \mathrm{mg} / \mathrm{kg}) 2 \mathrm{~h}$ post infection. This protective effect of verine was better than doripenem ( $50 \%$ protection) at the same dose. Likewise, we observed a significant decrease in bacterial burden (1-4 logs) in a variety of murine organs, including the spleen, lung, kidney, and liver, when treated either intraperitoneally or intravenously [27]. These results document direct antimicrobial efficacy for AMPs.

Other laboratories have primarily used normal (non-neutropenic) mice to test peptide efficacy. In such a model, the peptide may achieve efficacy by direct killing and/or immune boosting. Usually, a high bacterial inoculum is required for infection (e.g., $\sim 10^{8} \mathrm{CFU}$ for MRSA and $\sim 10^{7} \mathrm{CFU}$ for $P$. aeruginosa). Deslouches et al. [24] observed a systemic effect for WLBU2 treated i.v. at $3 \mathrm{mg} / \mathrm{kg} 30$ to $45 \mathrm{~min}$ after $P$. aeruginosa i.p. infection. No bacteria were recovered after 7 to 10 days from tissues or blood. Several peptides derived from proline-rich AMPs show systemic efficacy in mice infected intraperitoneally. Examples include A3-APO, Onc72, Onc112, and Api137 (Table 1). The designer peptide, A3-APO, is effective in multiple models to protect mice from E. coli Neumann infection in a dose-dependent manner. At $10 \mathrm{mg} / \mathrm{kg}$, it was as efficacious as imipenem in the long term. However, s.c. treatment was found to be ineffective against $E$. coli. The i.p. efficacy is proposed to result from both direct killing and immune-stimulatory effects [17]. Onc72 and Onc112 ( 2.5 or $5 \mathrm{mg} / \mathrm{kg}$ injected i.p. at 1, 4, and $8 \mathrm{~h}$ post-infection) were able to protect mice in a septicaemia model due to E. coli ATCC 25922 infection [18]. Api137 (an apidaecin derived peptide) showed a dose-dependent protection of the CD-1 mice ( $67 \%$ survival over 5 days) from E. coli ATCC 25922 infection when treated subcutaneously but not intravenously [42]. Although the minimal bactericidal 
concentrations (MBC) of AMPR-11 are moderate $(\sim 50 \mu \mathrm{M})$, it increases mouse survival rate by $60 \%$ after a single dose $(10 \mathrm{mg} / \mathrm{kg}$, i.v.) treatment one-hour post-infection with $S$. aureus, Pseudomonas aeruginosa, $K$. pneumoniae, or Acinetobacter baumannii [21]. This efficacy is comparable to that achieved by imipenem injected four times (every $12 \mathrm{~h}$, i.p.) $24 \mathrm{~h}$ post-infection. It is proposed that the observed efficacy results from multiple factors, including rapid killing, a lack of binding to serum/lipoproteins, and lipopolysaccharides (LPS) neutralization. Although not discussed, peptide-induced immune stimulation as evidenced by LPS neutralization could also be an important factor. Zhang et al. [43] observed a 2-3 log CFU decrease (relative to PBS treated) in mice injected with DP7 (2 mg/kg, i.v.) one-hour post i.v. infection similar to vancomycin at $10 \mathrm{mg} / \mathrm{kg}$. The RTD-1 peptide, a theta-defensin, shows systemic efficacy against intravenously infected Candida albicans when treated i.p. daily [44]. Interestingly, the treatment efficacy of RTD-1 at $5 \mathrm{mg} / \mathrm{kg}$ does not depend on administration routes. However, a further delay of treatment from 1, 3 , to $6 \mathrm{~h}$ after infection reduces peptide efficacy. The fact that the measured peptide concentrations in mice are 5-25 fold lower than MICs $(>100 \mu \mathrm{g} / \mathrm{mL})$ against $C$. albicans in the presence of $50 \%$ serum led to the conclusion that peptide efficacy did not result from direct antifungal effect. The same conclusion has been arrived in a recent study using MTD12813, an improved version of RTD-1, to treat mice (i.p.) infected with Gram-negative E. coli or K. pneumoniae (i.p.) [41]. Likewise, Rossi et al. [20] demonstrated the impact of gomesin (a scorpion peptide) on the host immune response against Candida infection in mice. In addition to bacterial killing [23], Li et al. [45] showed that OH-CATH30, a snake antimicrobial peptide, also induces an innate immune response to help the host combat bacterial infection. These examples indicate that AMPs can selectively boost the host immune response by regulating the release of proinflammatory cytokines and chemokines and promoting the chemotaxis of immune cells $[45,46]$.

In summary, these examples underscore the feasibility of identifying systemic AMPs. The systemic efficacy of these peptides could result from direct antimicrobial killing, immune stimulation, or a combination of the two mechanisms. In addition, in vivo efficacy could depend on experimental conditions. For instance, cyclic peptides were effective when administered intravenously but not orally or subcutaneously [37]. If we define the selectivity index as the ratio between the MTD and peptide treatment dose, there is a therapeutic window of up to 10 for these peptides to treat bloodstream infections (Table 1) and up to 100 to treat animals intraperitoneally [41].

\section{Peptide pharmacokinetics and pharmacodynamics}

The PK and PD data for antimicrobial peptides are very limited. Dartois and colleagues [37] followed the serum concentrations of peptides 6752 and 6853 after treatment at different doses. Maximum concentration $\left(C_{\max }\right)$ and the area under the concentration-time curve (AUC) increased steadily after injection from 2 to $8 \mathrm{mg} / \mathrm{kg}$. In contrast, peptides 1316 and 1150, which did not display in vivo efficacy, showed significantly lower $C_{\max }$ values, indicating the need for a sufficient amount of peptide (e.g., above MIC) for in vivo bacterial elimination. The $t_{1 / 2}$ values for these cyclic peptides ranged from 1.2 to $3.9 \mathrm{~h}$. Consistent with in vitro results, the in vivo anti-MRSA effect of the peptide did not depend on the susceptibility of bacteria to conventional antibiotics. The faster killing by peptide 6752 (membrane disruption) than vancomycin and oxacillin (cell wall inhibition) in vivo is consistent with their mechanisms of action. Interestingly, when treated at $16 \mathrm{mg} / \mathrm{kg}$ in the thigh model, the prolonged antibacterial activity (PAE) was greater than $6 \mathrm{~h}$ for vancomycin and $>7 \mathrm{~h}$ for 6752. A significant amount of the peptide was cleared renally. Ling et al. [38] showed that intravenous injection of a single dose of teixobactin $(20 \mathrm{mg} / \mathrm{kg})$ resulted in serum concentrations above the MIC for $4 \mathrm{~h}$, explaining the peptide efficacy in vivo. Schmidt et al. [19] also showed that when Api88 or Api137 was injected i.v. or i.p. at doses of 5 and $20 \mathrm{mg} / \mathrm{kg}$, their 
plasma levels were similarly low $(<3 \mu \mathrm{g} / \mathrm{mL})$. Comparable levels of these peptides accompanied by the same major metabolites were detected in blood, urine, kidney, and liver homogenates. Api137 was rapidly degraded at the C-terminus, while Api88 was rather stable. The high efficacy in murine infection models and the rapid clearance $(60-90 \mathrm{~min})$ of these peptides indicate that their in vivo efficacy is also related to the $C_{\max }$. Rossi et al. [20] found that gomesin mainly accumulated in the liver and rapidly eliminated from the circulation. However, the excretion route remained unexplored. In our recent study [27], we observed different half lives for the L- and D-forms of horine $\left(t_{1 / 2} \sim 10 \mathrm{~min}\right.$ and $\left.\sim 1 \mathrm{~h}\right)$ in murine blood after i.v. injection and a decrease in the amount of the peptide in blood is accompanied by an increase in other organs, including the spleen, lung, kidney, and liver. While the plasma level of $D$-horine remains above the MIC $(4 \mu \mathrm{M})$ for about one hour, the L-form of horine is rapidly degraded. The fact that both peptides demonstrate in vivo efficacy indicates rapid bacterial killing by horine, consistent with in vitro findings [27].

\section{Concluding remarks and future directions}

There is a clear need for systemic antimicrobials to treat bloodstream infections caused by antibioticresistant pathogens, such as bacteria, fungi, and parasites. Our establishment of a pipeline of peptide filters from in vitro to in vivo, inspired by our in silico filtering technology, presents a useful strategy for identifying additional systemic candidates to treat bloodstream infections [25]. In several cases, evidence has been obtained for the establishment of systemic bacterial infections before treatment. Based on limited systemic examples summarized here, we conclude that not all AMPs are able to display systemic efficacy in vivo. Some notable features for these systemic peptides in Table 1 are (1) low hydrophobic Prorich peptides, (2) low cationic database-derived peptides, and (3) cyclic peptides. Also, a small size is preferred to reduce production costs. It is proposed that a compact structure can reduce potential binding to other molecules. Such features might have improved the bioavailability of these peptides in vivo. In addition, the systemic effect of a peptide may depend on the type of animal models, bacteria species, bacterial inoculum, treatment time post-infection, peptide dose, and treatment frequency. It is clear in each case that a sufficient amount of antimicrobials is required to achieve in vivo efficacy. Therefore, further studies are required:

1. To identify the in vitro conditions useful for identifying systemic peptides;

2. To evaluate peptide toxicity more completely by using a variety of mammalian cell lines and animal models; and

3. To characterize the PK/PD properties of the identified AMP candidates since only limited data are available at present.

Finally, one can also learn from the peptide antibiotics already in clinical use (Table 2). These include vancomycin, daptomycin, colistin, and their derivatives recently approved by FDA. These peptide-based antibiotics are characterized by high efficacy and selectivity, low toxicity, low metabolic stability, and rapid renal clearance [42]. Notably, most known peptide antibiotics are cyclic and differ from the classic amphipathic helical peptides. Hence, we anticipate more attention to cyclic peptides in developing a new generation of future antibiotics. We also anticipate a continued search of novel peptide structures in nature by combining genetic, bioinformatic, proteomic, and structural biology approaches. It is proposed that a combination of AMPs with existing antibiotics can bring forth additional treatment benefits otherwise unachievable $[4,47]$. An improved understanding of AMPs in the host as well as in association with microbiota will contribute to future personal and precise medicine. 
Table 1. Antimicrobial peptides with systemic efficacy

\begin{tabular}{|c|c|c|c|c|c|c|c|c|}
\hline 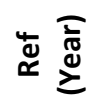 & 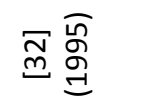 & 㐫 $\underset{\widetilde{d}}{\overline{\widetilde{d}}}$ & 守高 & 召 & & ฐ & 守总 & 可总 \\
\hline$\frac{0}{\frac{2}{2}}$ & 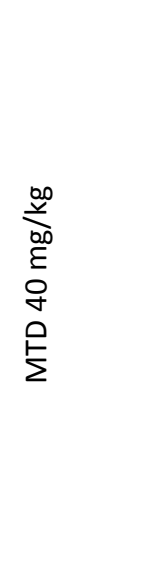 & 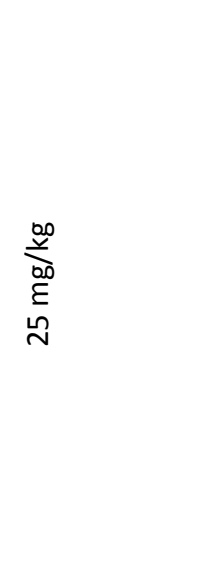 & z & 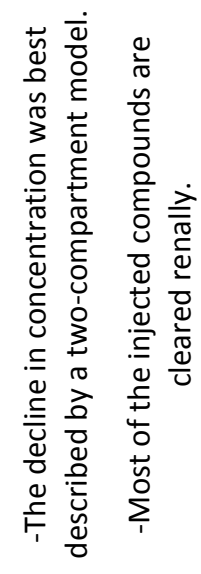 & 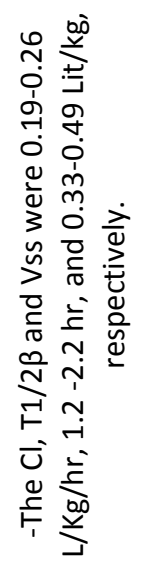 & 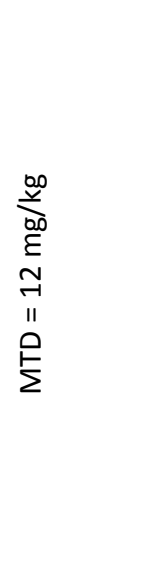 & 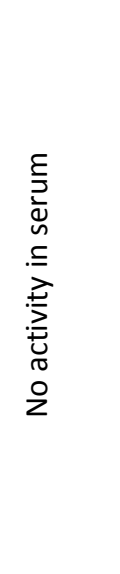 & 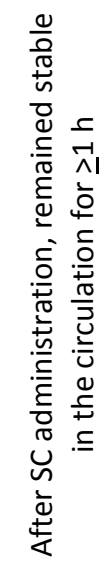 \\
\hline 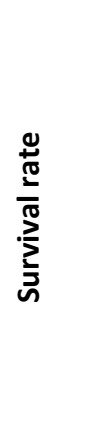 & 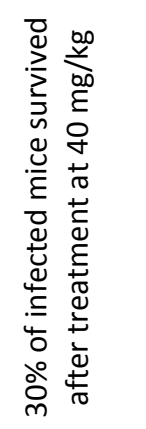 & 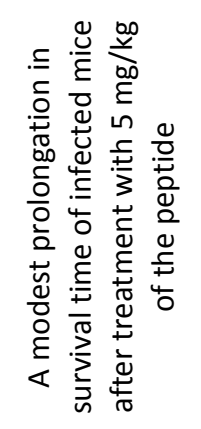 & 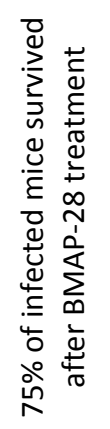 & z & & z & z & 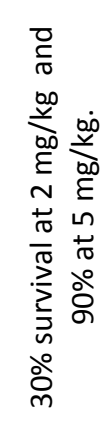 \\
\hline 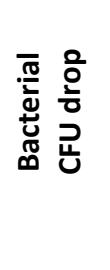 & ' & ' & $\frac{0_{0}^{\infty}}{i^{2}}$ & 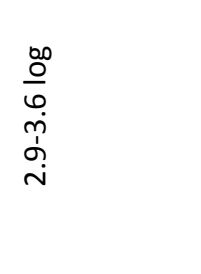 & & 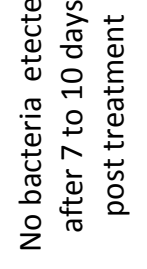 & $\frac{\infty 00}{-1}$ & $\frac{\stackrel{00}{m}}{e^{2}}$ \\
\hline 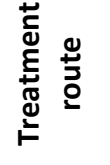 & $\geq$ & $\geq$ & $\geq$ & $\geq$ & & $\geq$ & $\geq$ & $\underset{\vdots}{\geqq}$ \\
\hline $\begin{array}{l}\text { 总 } \\
\text { 总 } \\
\underline{\underline{z}}\end{array}$ & $\geq$ & $\geq$ & $\geq$ & $\leqq$ & & $\cong$ & $\geq$ & $\sum_{\varrho}$ \\
\hline 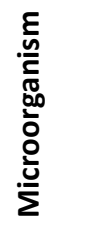 & 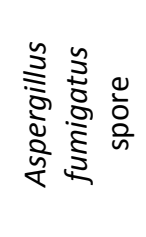 & 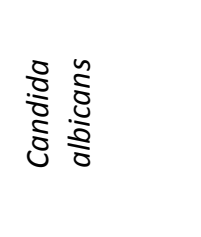 & 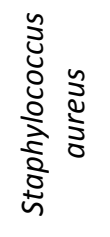 & 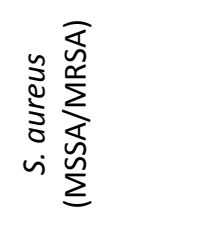 & & 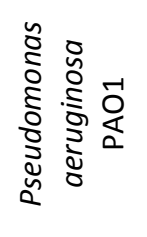 & 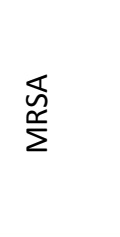 & 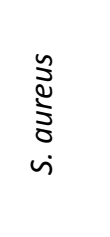 \\
\hline$\stackrel{\Xi}{\Sigma}$ & 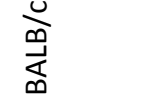 & $\stackrel{\ddot{\check{\Sigma}}}{\check{\Sigma}}$ & $\stackrel{\frac{0}{m}}{\frac{\omega}{\omega}}$ & $\stackrel{\ddot{\Sigma}}{\Sigma}$ & & 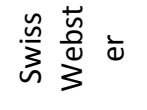 & $\stackrel{\ddot{\nu}}{\Sigma}$ & $\stackrel{\check{\Sigma}}{\Sigma}$ \\
\hline 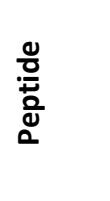 & 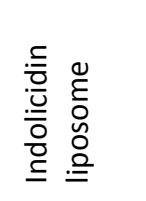 & $\frac{\bar{\infty}}{\bar{a}}$ & \begin{tabular}{l}
$\infty$ \\
\multirow{2}{1}{} \\
$\sum_{\infty}^{5}$
\end{tabular} & $\begin{array}{l}\tilde{N} \\
\hat{0} \\
\frac{\tilde{U}}{\bar{J}} \\
\hat{U}\end{array}$ & & $\stackrel{\mathrm{m}}{\mathrm{m}}_{3}^{\mathrm{N}}$ & 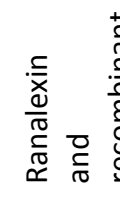 & 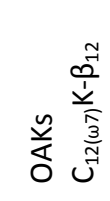 \\
\hline
\end{tabular}


Table 1. Continued...

\begin{tabular}{|c|c|c|c|c|c|c|c|c|c|}
\hline$\underset{\mathscr{q}}{\stackrel{4}{*}}$ & 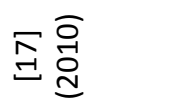 & 콩 엉 & 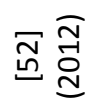 & ㅇㅓㅀㅠㅀ & 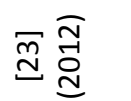 & 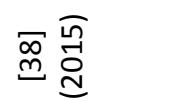 & 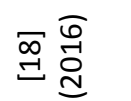 & 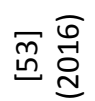 & \\
\hline$\frac{a}{\frac{a}{a}}$ & 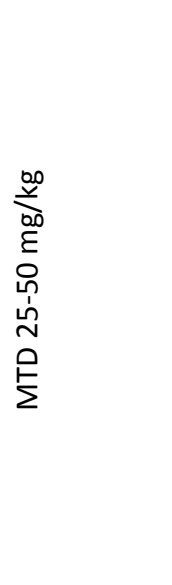 & 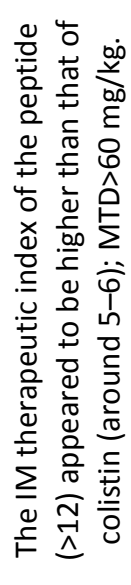 & 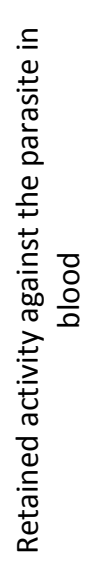 & 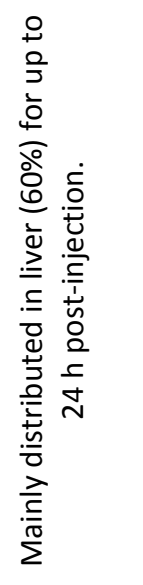 & 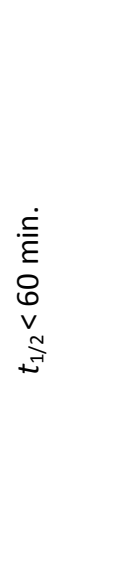 & 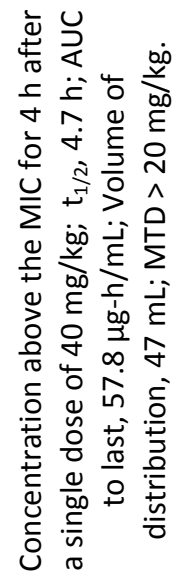 & 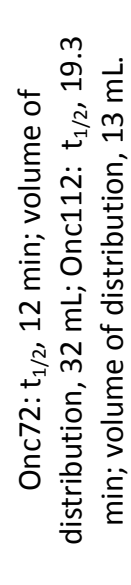 & 足 & 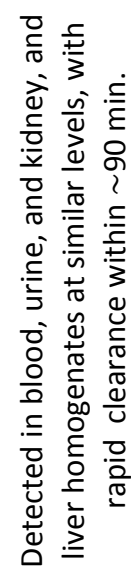 \\
\hline 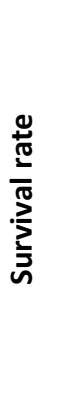 & 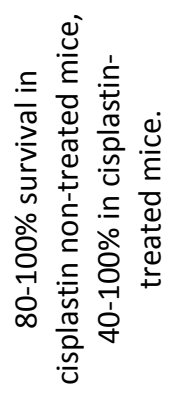 & 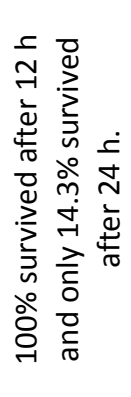 & 吕 & 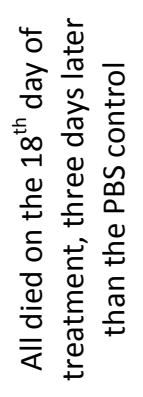 & 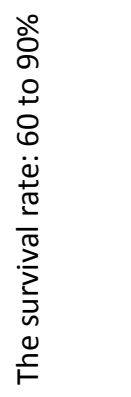 & 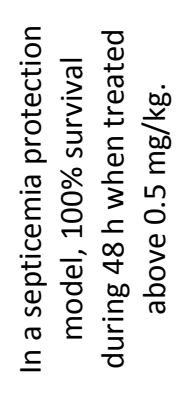 & 之 & 足 & ठి̊ \\
\hline 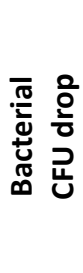 & 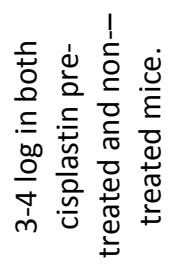 & $\begin{array}{l}\stackrel{0}{0} \\
\text { กै } \\
\text { ก่ }\end{array}$ & 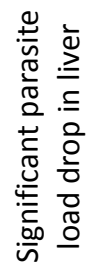 & $\begin{array}{l}\text { 음 } \\
\text { 굴 } \\
\text { ம் }\end{array}$ & $\begin{array}{l}\infty 00 \\
\frac{0}{n} \\
\dot{y} \\
\dot{y}\end{array}$ & 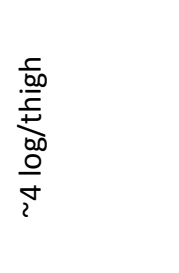 & 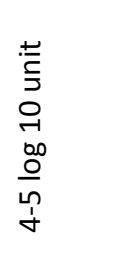 & 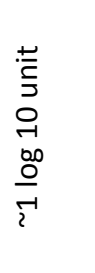 & 之 \\
\hline 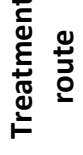 & 으 & 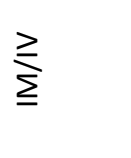 & $\geq$ & $\cong$ & 으 & $\geq$ & $\underline{\underline{ }}$ & $\geq$ & $\cong$ \\
\hline 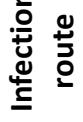 & $\underline{\underline{ }}$ & $\cong$ & $\geq$ & $\geq$ & $\cong$ & $\cong$ & $\cong$ & 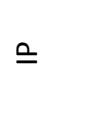 & $\cong$ \\
\hline 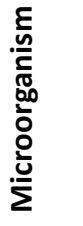 & 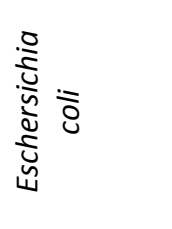 & 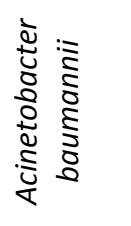 & 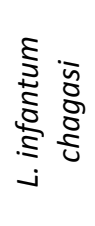 & \begin{tabular}{ll}
0 & \multicolumn{2}{c}{} \\
0 & 5 \\
0 & 0 \\
0 & 0 \\
0 & 0 \\
0
\end{tabular} & 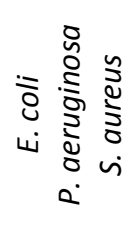 & $\begin{array}{l}\text { 茂 } \\
\stackrel{n}{\Sigma}\end{array}$ & نَ & $\begin{array}{l}\stackrel{\nwarrow}{n} \\
\stackrel{\leftarrow}{\Sigma}\end{array}$ & ن̀ \\
\hline$\stackrel{\stackrel{\Perp}{\Sigma}}{\Sigma}$ & $\sum_{\text {站 }}^{-1}$ & 仓े & $\frac{0}{\frac{0}{\alpha}}$ & $\frac{u}{\stackrel{0}{\frac{1}{0}}}$ & $\stackrel{\stackrel{U}{z}}{\Sigma}$ & 仓े & $\stackrel{\mathscr{U}}{\stackrel{\Sigma}{\Sigma}}$ & $\stackrel{\stackrel{U}{\varrho}}{\Sigma}$ & $\stackrel{\mathscr{U}}{\Sigma}$ \\
\hline$\frac{\frac{1}{2}}{\frac{0}{0}}$ & 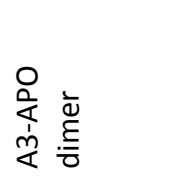 & 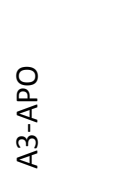 & $\begin{array}{l}\overrightarrow{1} \\
\frac{1}{x}\end{array}$ & 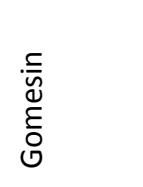 & 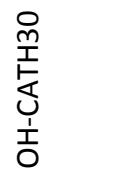 & 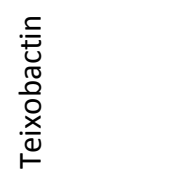 & 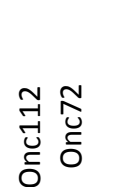 & 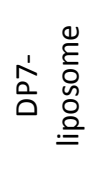 & 辛 \\
\hline
\end{tabular}


Table 1. Continued...

\begin{tabular}{|c|c|c|c|c|c|c|c|c|}
\hline 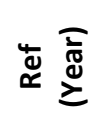 & F & 寻总 & $\underset{\mathcal{g}}{\stackrel{\sigma}{\vec{Q}}}$ & 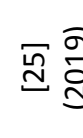 & 怘 & 氙弇 & 承鸽 & 忞仝 \\
\hline$\frac{\stackrel{\circ}{\frac{2}{a}}}{\frac{2}{2}}$ & 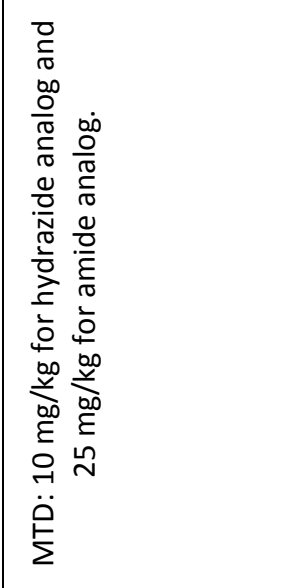 & 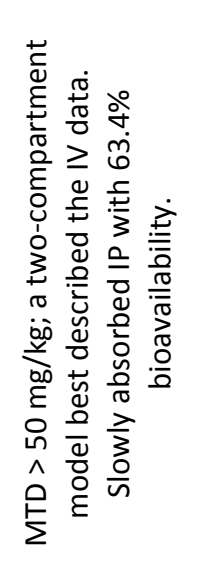 & 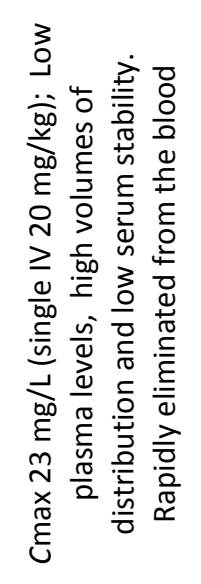 & $\hat{z}$ & z & z & & 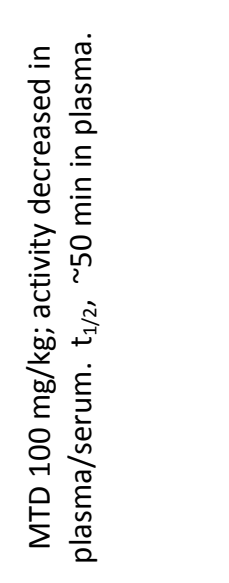 \\
\hline 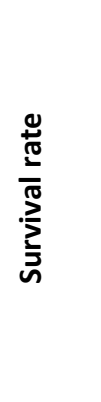 & 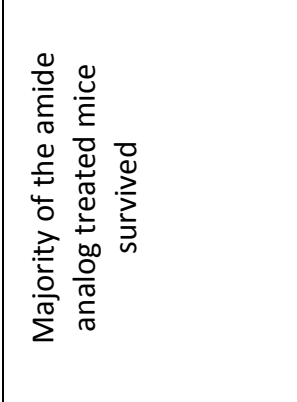 & 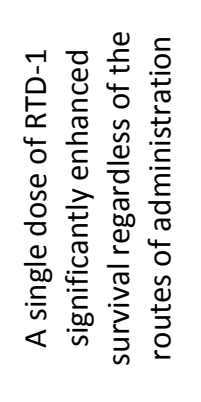 & 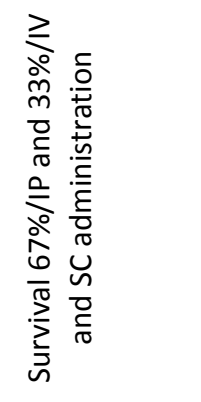 & $\hat{z}$ & z & 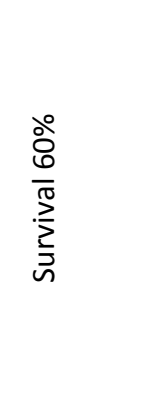 & 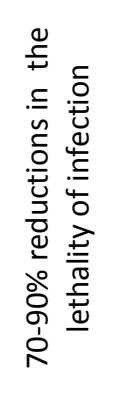 & 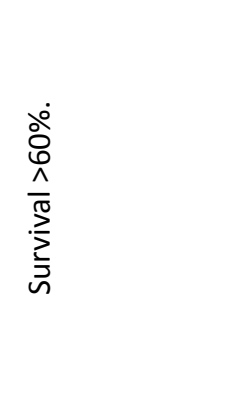 \\
\hline 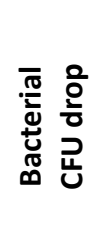 & 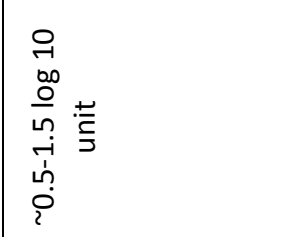 & $\begin{array}{l}\frac{0}{0} \\
\frac{0}{00} \\
\frac{0}{m} \\
\frac{1}{2} \\
i\end{array}$ & 之 & 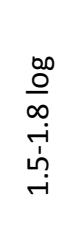 & 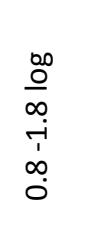 & & 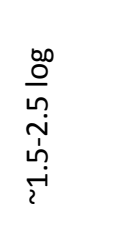 & $\begin{array}{l}\frac{00}{0} \\
\frac{1}{1} \\
\stackrel{4}{0} \\
?\end{array}$ \\
\hline 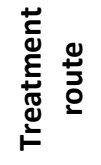 & $\leqq$ & 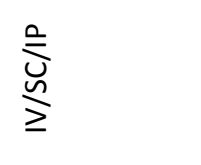 & $\stackrel{u}{\underline{M}}$ & 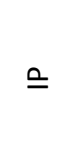 & $\cong$ & $\geq$ & $\geq$ & $\geq$ \\
\hline 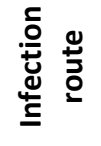 & $\cong$ & $\geq$ & $\cong$ & $\cong$ & $\cong$ & $\underline{z}$ & $\geq$ & $\geq$ \\
\hline 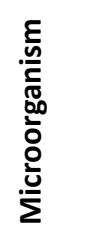 & 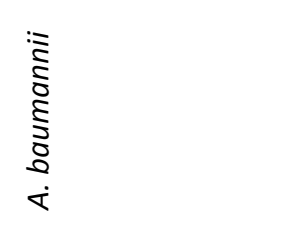 & 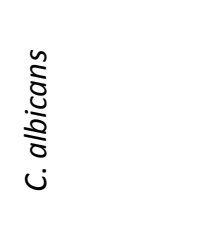 & نे & 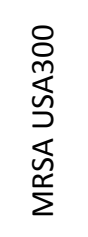 & 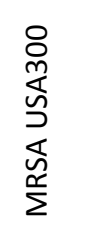 & 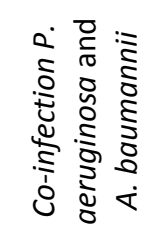 & 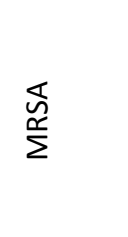 & 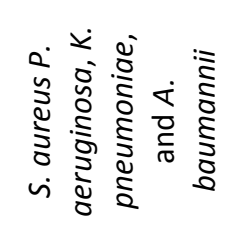 \\
\hline$\stackrel{\check{\Sigma}}{\Sigma}$ & $\stackrel{\mathscr{\nu}}{\Sigma}$ & $\vec{\theta}$ & $\sum_{z}^{\bar{x}}$ & 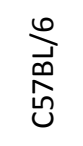 & 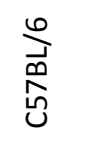 & $\stackrel{\frac{u}{m}}{\frac{9}{\infty}}$ & 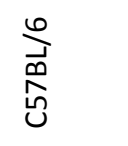 & 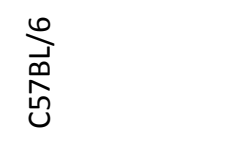 \\
\hline$\frac{\frac{8}{0}}{\frac{0}{\alpha}}$ & 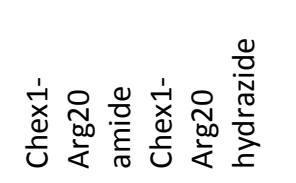 & 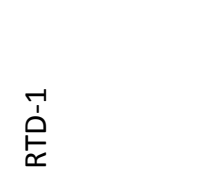 & $\frac{\hat{q}}{\frac{\pi}{8}}$ & $\begin{array}{l}\text { O⿱丷⿹弔㇒ } \\
\text { 点 }\end{array}$ & $\begin{array}{l}\overrightarrow{0} \\
\vec{h} \\
\vec{\Delta}\end{array}$ & 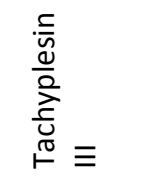 & $\hat{a}$ & $\begin{array}{l}-7 \\
\substack{1 \\
\alpha} \\
\sum_{<}^{0}\end{array}$ \\
\hline
\end{tabular}


Table 1. Continued...

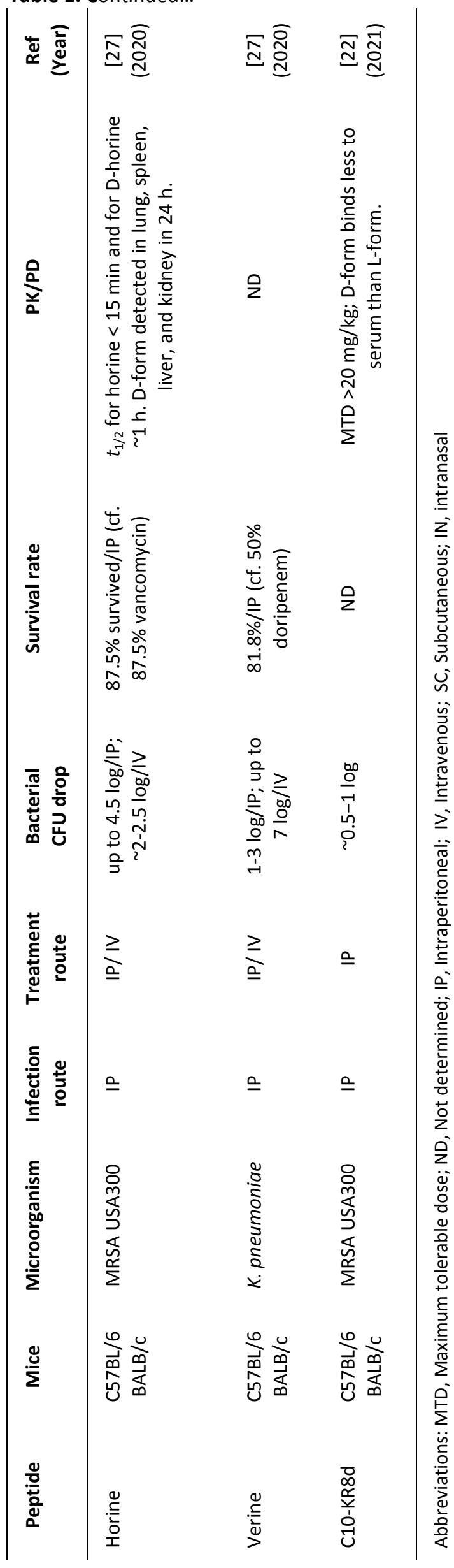


Table 2. Clinically used peptide antibiotics for systemic and skin infections ${ }^{1}$

\begin{tabular}{|c|c|c|c|c|c|c|c|c|}
\hline $\begin{array}{l}\text { 임 } \\
\frac{0}{0} \\
\frac{0}{2}\end{array}$ & 六 & ন্ণ & $\begin{array}{l}\infty \\
\text { ஸે } \\
\text { - }\end{array}$ & 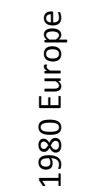 & 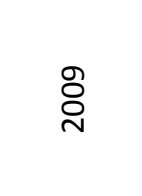 & 귬 & 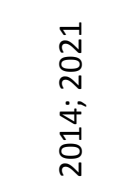 & 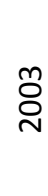 \\
\hline 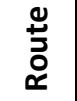 & $\geq$ & $\geq$ & $\geq$ & $\begin{array}{l}\geq \\
\underline{\Sigma}\end{array}$ & $\geq$ & $\geq$ & $\geq$ & $\geq$ \\
\hline 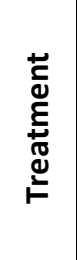 & 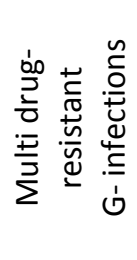 & 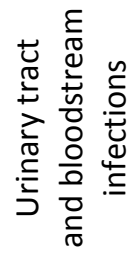 & 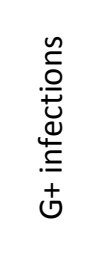 & 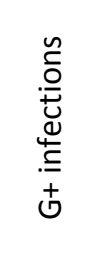 & 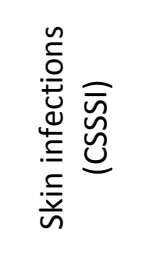 & 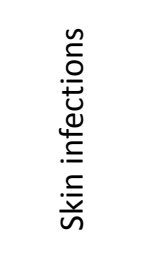 & 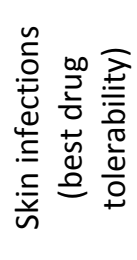 & 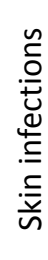 \\
\hline$\stackrel{\nwarrow}{\text { O }}$ & $\begin{array}{l}\frac{n}{n} \\
\frac{n}{2} \\
\frac{n}{0} \\
\frac{0}{0} \\
\frac{c}{0} \\
\sum\end{array}$ & $\begin{array}{l}\frac{n}{n} \\
\frac{n}{2} \\
\frac{c}{n} \\
\frac{0}{2} \\
\frac{0}{E} \\
\sum\end{array}$ & 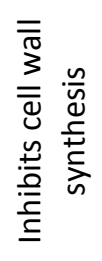 & 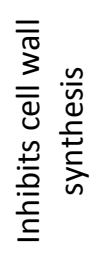 & 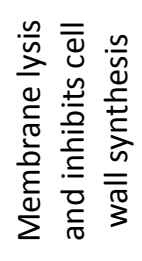 & 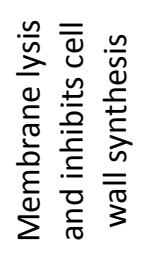 & 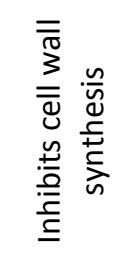 & 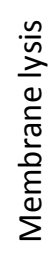 \\
\hline 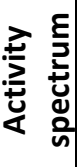 & ن́ & ن́ & $\stackrel{+}{*}$ & $\stackrel{+}{*}$ & $\stackrel{+}{\cup}$ & $\stackrel{+}{0}$ & 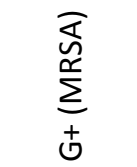 & $\stackrel{+}{0}$ \\
\hline $\begin{array}{l}\tilde{y} \\
\frac{\mathscr{c}}{U}\end{array}$ & $\begin{array}{l}\frac{0}{0} \\
\frac{0}{1} \\
\frac{0}{0} \\
\frac{0}{0} \\
\frac{0}{3}\end{array}$ & $\begin{array}{l}\frac{0}{0} \\
\frac{0}{1} \\
00 \\
0 \\
00 \\
0 \\
. \frac{0}{3}\end{array}$ & $\begin{array}{l}\frac{0}{0} \\
\frac{0}{2} \\
0 \\
0 \\
0 \\
0 \\
0 \\
\frac{0}{2}\end{array}$ & $\begin{array}{l}\frac{0}{0} \\
\frac{0}{2} \\
\frac{0}{0} \\
\frac{0}{0} \\
\frac{0}{1}\end{array}$ & 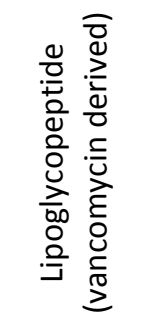 & 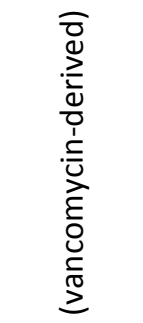 & 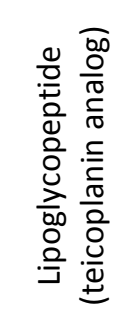 & $\begin{array}{l}\frac{0}{0} \\
. \frac{0}{0} \\
\frac{0}{0} \\
\frac{0}{0} \\
. \frac{2}{3}\end{array}$ \\
\hline 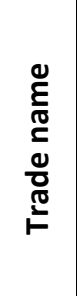 & 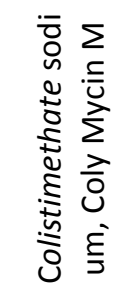 & 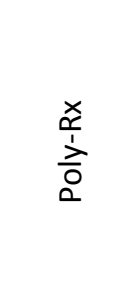 & 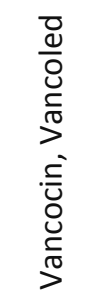 & 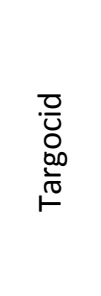 & $\begin{array}{l}\stackrel{3}{0} \\
\stackrel{0}{0} \\
\stackrel{3}{>}\end{array}$ & 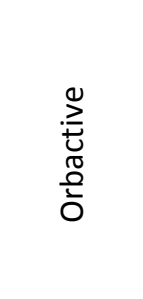 & 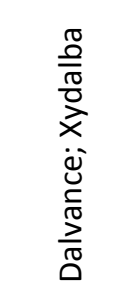 & $\frac{\cdot \frac{1}{0}}{\frac{U}{J}}$ \\
\hline 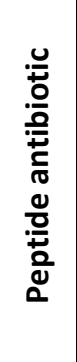 & 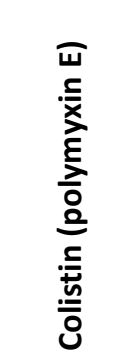 & 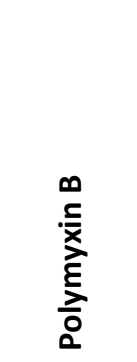 & 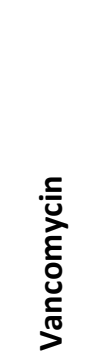 & $\begin{array}{l}\frac{5}{\frac{0}{0}} \\
\frac{\pi}{0} \\
\frac{0}{0} \\
\frac{0}{1}\end{array}$ & 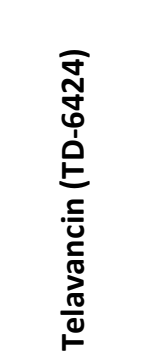 & 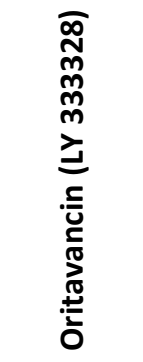 & 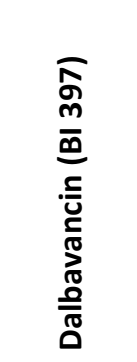 & 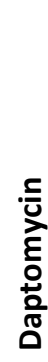 \\
\hline
\end{tabular}


Conflict of interest: The authors declare no conflict of interest

Acknowledgement: This study is supported by the grants from the NIH (GM138552) and the state of Nebraska

\section{References}

[1] J. O'Neil, The Review on Antimicrobial Resistance: Tracking Drug-resistant Infections Globally. UK (2014). https://amr-review.org/sites/default/files/160518 Final\%20paper with\%20cover.pdf.

[2] H.G. Boman. Antibacterial peptides: basic facts and emerging concepts. Journal of Internal Medicine 254 (2003) 197-215. https://doi.org/10.1046/j.1365-2796.2003.01228.x.

[3] M. Zasloff. Antimicrobial peptides of multicellular organisms. Nature 415 (2002) 389-395. https://doi.org/10.1038/415389a.

[4] B. Mishra, S. Reiling, D. Zarena, G. Wang. Host defense antimicrobial peptides as antibiotics: design and application strategies. Current Opinion in Chemical Biology 38 (2017) 87-96. https://doi.org/10.1016/j.cbpa.2017.03.014.

[5] Z. Wang, G. Wang. APD: the antimicrobial peptide database. Nucleic Acids Research 32 (2004) D590D592. https://doi.org/10.1093/nar/gkh025.

[6] G. Wang, C.M. Zietz, A. Mudgapalli, S. Wang, Z. Wang. The evolution of the antimicrobial peptide database over 18 years: Milestones and new features. Protein Science 31 (2022) 92-106. https://doi.org/10.1002/pro.4185.

[7] G. Wang. Structures of human host defense Cathelicidin LL-37 and its smallest antimicrobial peptide $\mathrm{kr}-12$ in lipid structures of human host defense Cathelicidin LL-37 and its smallest antimicrobial peptide KR-12 in lipid micelles. The Journal of Biological Chemistry 283 (2008) 32637-32643. https://doi.org/10.1074/jbc.M805533200.

[8] G. Wang. Unifying the classification of antimicrobial peptides in the antimicrobial peptide database. Methods in Enzymology (2021). In press. https://doi.org/10.1016/bs.mie.2021.09.006.

[9] R.I. Lehrer, W. Lu. $\alpha$-Defensins in human innate immunity. Immunological Reviews 245 (2012) 84112. https://doi.org/10.1097/MOH.0000000000000005.

[10] G. Diamond, L. Ryan. Beta-defensins: what are they really doing in the oral cavity? Oral Diseases 17 (2011) 628-635. https://doi.org/10.1111/j.1601-0825.2011.01799.x.

[11] M. Graf, M. Mardirossian, F. Nguyen, A.C. Seefeldt, G. Guichard, M. Scocchi, C.A. Innis, D.N. Wilson. Proline-rich antimicrobial peptides targeting protein synthesis. Natural Product Reports 34 (2017) 702-711. https://doi.org/10.1039/c7np00020k.

[12] R.M. Epand, H.J. Vogel. Diversity of antimicrobial peptides and their mechanisms of action. Biochimica et Biophysica Acta 1462 (1999)11-28. https://doi.org/10.1016/s0005-2736(99)00198-4.

[13] A. Makovitzki, D. Avrahami, Y. Shai. Ultrashort antibacterial and antifungal lipopeptides. Proceedings of the National Academy of Sciences 103 (2006) 15997-60002. https://doi.org/10.1073/pnas.0606129103.

[14] G. Wang, J.L. Narayana, B. Mishra, Y. Zhang, F. Wang, C. Wang, D. Zarena, T. Lushnikova, X. Wang. Design of antimicrobial peptides: Progress made with human Cathelicidin LL-37. In: Matsuzaki K. (eds) Antimicrobial Peptides. Advances in Experimental Medicine and Biology 1117 (2019) 215-240. https://doi.org/10.1007/978-981-13-3588-4 12.

[15] X. Li, Y. Li, H. Han, D.W. Miller, G. Wang. Solution structures of human LL-37 fragments and NMRbased identification of a minimal membrane-targeting antimicrobial and anticancer region. Journal of the American Chemical Society 128 (2006) 5776-5785. https://doi.org/10.1021/ia0584875.

[16] Qin, H. Fang, X. Chen, L. Wang, C. Ma, X. Xi, T. Chen, C. Shaw, M. Zhou. Exploration of the structurefunction relationships of a novel frog skin secretion-derived bioactive peptide, t-DPH1, through use of rational design, cationicity enhancement and in vitro studies. Antibiotics 10 (2021) 1529. https://doi.org/10.3390/antibiotics10121529. 
[17] D. Szabo' E. Ostorhazi, A. Binas, F. Rozgonyi, B. Kocsis, M. Cassone, J.D. Wade, O. Nolte, L. Otvos . The designer proline-rich antibacterial peptide A3-APO is effective against systemic Escherichia coli infections in different mouse models. International Journal of Antimicrobial Agents 35 (2010) 357361. https://doi.org/10.1016/j.ijantimicag.2009.10.015.

[18] R. Schmidt, E. Ostorházi, E. Wende, D. Knappe, R. Hoffmann. Pharmacokinetics and in vivo efficacy of optimized oncocin derivatives. Journal of Antimicrobial Chemotherapy 71 (2016) 1003-1011. https://doi.org/10.1093/jac/dkv454.

[19] R. Schmidt, D. Knappe, E. Wende, E. Ostorházi, R. Hoffmann. In vivo efficacy and pharmacokinetics of optimized apidaecin analogs. Frontiers in Chemistry 5 (2017) 15. https://doi.org/10.3389/fchem.2017.00015.

[20] D.C. Rossi, J.E. Muñoz, D.D. Carvalho, R. Belmonte, B. Faintuch, P. Borelli, A. Miranda, C.P. Taborda, S. Daffre. Therapeutic use of a cationic antimicrobial peptide from the spider Acanthoscurria gomesiana in the control of experimental candidiasis. BMC Microbiology 12 (2012) 28. https://doi.org/10.1186/1471-2180-12-28.

[21] H.R. Lee, D.G. You, H.K. Kim, J.W. Sohn, M.J. Kim, J.K. Park, G.Y. Lee, Y.D. Yoo. Romo1-derived antimicrobial peptide is a new antimicrobial agent against multidrug-resistant bacteria in a murine model of sepsis. mBio 11 (2020) e03258-19. https://doi.org/10.1128/mBio.03258-19.

[22] J. L. Narayana, R. Golla, B. Mishra, X. Wang, T. Lushnikova, Y. Zhang, A.Verma, V. Kumar, J. Xie, G. Wang. Short and robust anti-infective lipopeptides engineered based on the minimal antimicrobial peptide KR12 of Human LL-37. ACS Infectious Disease 7 (2021) 1795-1808. https://doi.org/10.1021/acsinfecdis.1c00101.

[23] S.A. Li, W.H. Lee, Y. Zhang. Efficacy of OH-CATH30 and its analogs against drug-resistant bacteria in vitro and in mouse models. Antimicrobial Agents and Chemotherapy 56 (2012) 33093317. https://doi.org/10.1128/AAC.06304-11.

[24] B. Deslouches, K. Islam, J.K. Craigo, S.M. Paranjape, R.C. Montelaro, T.A. Mietzner. Activity of the de novo engineered antimicrobial peptide WLBU2 against Pseudomonas aeruginosa in human serum and whole blood: implications for systemic applications. Antimicrobial Agents and Chemotherapy $\mathbf{4 9}$ (2005) 3208-3216. https://doi.org/10.1128/AAC.49.8.3208-3216.2005.

[25] B. Mishra, J.L. Narayana, T. Lushnikova, X. Wang, G. Wang. Low cationicity is important for systemic in vivo efficacy of database-derived peptides against drug-resistant Gram-positive pathogens. Proceedings of the National Academy of Sciences 116 (2019) 13517-13522. https://doi.org/10.1073/pnas.1821410116.

[26] B. Mishra, G. Wang. Ab initio design of potent anti-MRSA peptides based on database filtering technology. Journal of the American Chemical Society 134 (2012) 12426-12429. https://doi.org/10.1021/ja305644e.

[27] J.L. Narayana, B. Mishra, T. Lushnikova, Q. Wu, Y.S. Chhonkerb, Y.Zhang, D. Zarena, E.S. Salnikov, X. Dang, F. Wang, C. Murphy, K.W. Foster, S. Gorantla, B. Bechinger, D.J. Murry, G. Wang. Two distinct amphipathic peptide antibiotics with systemic efficacy. Proceedings of the National Academy of Sciences 117 (2020) 19446-19454. https://doi.org/10.1073/pnas.2005540117.

[28] G. Wang. Post-translational modifications of natural antimicrobial peptides and strategies for peptide engineering. Current Biotechnology 1 (2012) 72-79. https://doi.org/10.2174/2211550111201010072.

[29] B.P. Mowery, S.E. Lee, D.A. Kissounko, R.F. Epand, R.M. Epand, B. Weisblum, S.S. Stahl, S.H. Gellman. Mimicry of antimicrobial host-defense peptides by random copolymers. Journal of the American Chemical Society 129 (2007) 15474-15476. https://doi.org/10.1021/ja077288d.

[30] R.W. Scott, W.F. DeGrado, G.N. Tew. De novo designed synthetic mimics of antimicrobial peptides. Current Opinion in Biotechnology 19 (2008) 620-627. https://doi.org/10.1016/j.copbio.2008.10.013.

[31] I.S. Radzishevsky, S. Rotem, D. Bourdetsky, S. Navon-Venezia, Y. Carmeli, A. Mor. Improved antimicrobial peptides based on acyl-lysine oligomers. Nature Biotechnology 25 (2007) 657659. https://doi.org/10.1038/nbt1309. 
[32] I. Ahmad, W.R. Perkins, D.M. Lupan, M.E. Selsted, A.S. Janoff. Liposomal entrapment of the neutrophil-derived peptide indolicidin endows it with in vivo antifungal activity. Biochimica et Biophysica Acta (BBA) - Biomembranes 1237 (1995) 109-114. https://doi.org/10.1016/00052736(95)00087-j.

[33] X. Liu, Z. Li, X. Wang, Y. Chen, F. Wu, K. Men, T. Xu, Y. Luo, L.Yang. Novel antimicrobial peptidemodified azithromycin-loaded liposomes against methicillin-resistant Staphylococcus aureus. International Journal of Nanomedicine 11 (2016) 6781-6794. https://doi.org/10.2147/ijn.s107107.

[34] J. Johansson, G.H. Gudmundsson, M.E. Rottenberg, K.D. Berndt, B. Agerberth. Conformationdependent antibacterial activity of the naturally occurring human peptide LL-37. Journal of Biological Chemistry 273 (1998) 3718-3724. https://doi.org/10.1074/ibc.273.6.3718.

[35] F. Jafari, S. Elyasi. Prevention of colistin induced nephrotoxicity: a review of preclinical and clinical data. Expert Review of Clinical Pharmacology. 14 (2021) 1113-1131. https://doi.org/10.1080/17512433.2021.1933436.

[36] B.K. Prasannan, F.C. Mukthar, V.N. Unni, S. Mohan, K. Vinodkumar. Colistin Nephrotoxicity-Age and Baseline kidney Functions Hold the Key. Indian Journal of Nephrology. 31 (2021) 449-453. https://doi.org/10.4103/ijn.IJN 13020.

[37] V. Dartois, J. Sanchez-Quesada, E. Cabezas, E. Chi, C. Dubbelde, C. Dunn, J. Granja, C. Gritzen, D. Weinberge, M. R. Ghadiri, T.R. Parr. Systemic antibacterial activity of novel synthetic cyclic peptides Antimicrobial Agents and Chemotherapy 49 (2005) 3302-3310. https://doi.org/10.1128/AAC.49.8.3302-3310.2005.

[38] L.L. Ling, T. Schneider, A.J. Peoples, A.L. Spoering, I. Engels, B.P. Conlon, A. Mueller, T.F. Schäberle, D.E. Hughes, S. Epstein, M. Jones, L. Lazarides, V.A. Steadman, D.R. Cohen, C.R. Felix, K.A. Fetterman, W.P. Millett, A.G. Nitti, A.M. Zullo, C. Chen, K. Lewis. A new antibiotic kills pathogens without detectable resistance. Nature 517 (2015) 455-459. https://doi.org/10.1038/nature14098.

[39] J.W. Van t Wout, H. Mattie, R. van Furth. Comparison of the efficacies of amphotericin B, fluconazole, and itraconazole against a systemic Candida albicans infection in normal and neutropenic mice. Antimicrobial Agents and Chemotherapy 33 (1989) 147-151. https://doi.org/10.1128/AAC.33.2.147.

[40] C.B. Landersdorfer, J. Wang, V. Wirth, K. Chen, K.S. Kaye, B.T. Tsuji, J. Li, R.L. Nation. Pharmacokinetics/pharmacodynamics of systemically administered polymyxin B against Klebsiella pneumoniae in mouse thigh and lung infection models. Journal of Antimicrobial Chemotherapy $\mathbf{7 3}$ (2018) 462-468. https://doi.org/10.1093/jac/dkx409.

[41] J.B. Schaal, Y. Eriguchi, D.Q. Tran, P.A. Tran, C. Hawes, A.E. Cabebe, K. Pike, K. Trinh, A.J. Ouellette, M.E. Selsted. A host-directed macrocyclic peptide therapeutic for MDR gram negative bacterial infections. Scientific Reports 11 (2021) 23447. https://doi.org/10.1038/s41598-021-02619-y.

[42] D. Knappe, R. Schmidt, K. Adermann, R. Hoffmann. Continuous subcutaneous delivery of proline-rich antimicrobial peptide Api137 provides superior efficacy to intravenous administration in a mouse infection model. Frontiers in Microbiology 10 (2019) 2283. https://doi.org/10.3389/fmicb.2019 .02283$.

[43] R. Zhang, Z. Wang, Y. Tian, Q. Yin, X. Cheng, M. Lian, B. Zhou, X. Zhang, L. Yang. Efficacy of antimicrobial peptide dp7, designed by machine-learning method, against methicillin-resistant Staphylococcus aureus. Frontiers in Microbiology 10 (2019) 1175. https://doi.org/10.3389/fmicb.2019.01175.

[44] V. Basso, D.Q. Tran, J.B. Schaal, P. Tran, Y. Eriguchi, D. Ngole, A.E. Cabebe, A.Y. Ppark, P.M. Beringer, A.J. Ouellette, M.E. Selsted. Rhesus Theta defensin 1 promotes long term survival in systemic candidiasis by host directed mechanisms. Scientific Reports 9 (2019) 16905. https://doi.org/10.1038/s41598-019-53402-z.

[45] S.A. Li, Y. Xiang, Y.J. Wang, J. Liu, W.H. Lee, Y. Zhang. Naturally occurring antimicrobial peptide OHCATH30 selectively regulates the innate immune response to protect against sepsis. Journal of Medicinal Chemistry 56 (2013) 9136-9145. https://doi.org/10.1021/jm401134n. 
[46] N. Mookherjee, R.E. Hancock. Cationic host defence peptides: innate immune regulatory peptides as a novel approach for treating infections. Cellular and Molecular Life Sciences 64 (2007) 922-933. https://doi.org/10.1007/s00018-007-6475-6.

[47] A. Giacometti, O. Cirioni, R. Ghiselli, C. Bergnach, F. Orlando, G. D’Amato, F. Mocchegiani, C. Silvestri, M.S. Del Prete, B. Skerlavaj, V. Saba, M. Zanetti, G. Scalise. The antimicrobial peptide BMAP-28 reduces lethality in mouse models of Staphylococcal sepsis. Critical Care Medicine 32 (2004) 24852490. https://doi.org/10.1097/01.ccm.0000148221.09704.22.

[48] S. Pacor, A. Giangaspero, M. Bacac, G. Sava, A. Tossi. Analysis of the cytotoxicity of synthetic antimicrobial peptides on mouse leucocytes: implications for systemic use. Journal of Antimicrobial Chemotherapy 50 (2002) 339-348. https://doi.org/10.1093/jac/dkf141.

[49] A.P. Desbois, C.G. Gemmell, P.J. Coote. In vivo efficacy of the antimicrobial peptide ranalexin in combination with the endopeptidase lysostaphin against wound and systemic meticillin-resistant Staphylococcus aureus (MRSA) infections. International Journal of Antimicrobial Agents 35 (2010) 559-565. https://doi.org/10.1016/i.ijantimicag.2010.01.016.

[50] H. Sarig, L. Livne, V. Held-Kuznetsov, F. Zaknoon, A. Ivankin, D. Gidalevitz, A. Mor A miniature mimic of host defense peptides with systemic antibacterial efficacy. The FASEB Journal 24 (2010) 19041913. https://doi.org/10.1096/fj.09-149427.

[51] E. Ostorhazi, F. Rozgonyi, D. Szabo, A. Binas, M. Cassone,J.D. Wade, O. Nolte, C.R. Bethel, R.A. Bonomo, L,Otvos. Intramuscularly administered peptide A3-APO is effective against carbapenemresistant Acinetobacter baumannii in mouse models of systemic infections. Peptide Science 96 (2010) 126-129. https://dx.doi.org/10.1002/bip.21443.

[52] M.C. Erfe, C.V. David, C. Huang, V. Lu, A.C. Maretti-Mira, J. Haskell, K.W. Bruhn, M.R. Yeaman, N. Craft. Efficacy of synthetic peptides RP-1 and AA-RP-1 against Leishmania species in vitro and in vivo. Antimicrob Agents and Chemotherapy. 56 (2012) 658-665. https://doi.org/10.1128/AAC.05349-11.

[53] X. Liu, Z. Li, X. Wang, Y. Chen, F. Wu, K. Men, T. Xu, Y. Luo, L. Yang. Novel antimicrobial peptidemodified azithromycin-loaded liposomes against methicillin-resistant Staphylococcus aureus. International Journal of Nanomedicine. 11 (2016) 6781-6794. https://doi.org/10.2147/IJN.S107107.

[54] E. Ostorhazi, R. Hoffmann, N. Herth, J.D. Wade, C.N. Kraus, L. Otvos. Advantage of a narrow-spectrum host defense (antimicrobial) peptide over a broad spectrum analog in preclinical drug development. Frontiers in Chemistry 6 (2018) 359. https://doi.org/10.3389/fchem.2018.00359.

[55] J. Qi, R. Gao, C. Liu, B. Shan, F. Gao, J. He, M. Yuan, H. Xie, S. Jin, Y. Ma. Potential role of the antimicrobial peptide Tachyplesin III against multidrug-resistant $P$. aeruginosa and $A$. baumannii coinfection in an animal model. Infection and Drug Resistance 12 (2019) 2865-2874. https://doi.org$\angle 10.2147 /$ IDR.S217020.

(C)2022 by the authors; licensee IAPC, Zagreb, Croatia. This article is an open-access article distributed under the terms and conditions of the Creative Commons Attribution license (http://creativecommons.org/licenses/by/3.0/) (cc) EY 